\title{
Un ouvrage très populaire du 16e siècle, devenu très rare par la suite
}

Daniel Bornemann

\section{(2) OpenEdition \\ 1 Journals}

Édition électronique

URL : http://journals.openedition.org/rbnu/1433

DOI : 10.4000/rbnu. 1433

ISSN : 2679-6104

Éditeur

Bibliothèque nationale et universitaire de Strasbourg

\section{Édition imprimée}

Date de publication : 1 novembre 2015

Pagination : 114-115

ISBN : 9782859230616

ISSN : 2109-2761

\section{Référence électronique}

Daniel Bornemann, "Un ouvrage très populaire du 16e siècle, devenu très rare par la suite », La Revue de la BNU [En ligne], 12 | 2015, mis en ligne le 01 mars 2020, consulté le 13 décembre 2020. URL: http://journals.openedition.org/rbnu/1433; DOI : https://doi.org/10.4000/rbnu.1433

\section{(c) (i) (2) (2)}

La Revue de la BNU est mise à disposition selon les termes de la Licence Creative Commons Attribution - Pas d'Utilisation Commerciale - Partage dans les Mêmes Conditions 4.0 International. 


\section{NOUVELLES ACQUISITIONS PATRIMONIALES}

\section{Un ouvrage très populaire du $16^{\mathrm{e}}$ siècle, devenu très rare par la suite}

Von untrew der weyber, schoene gleichnussen der sieben Weisen Meyster. Imprimé à Strasbourg par Wendelin Rihel, en 1549.

Ce petit in-quarto appartient au domaine de la littérature populaire. Son auteur est inconnu. Il est orné d'une gravure au titre, qui est répétée plusieurs fois dans le volume, et compte dix gravures différentes en tout, avec de nombreuses répétitions. Sa reliure imite l'ancien style : basane estampée à la roulette, dos à trois nerfs, mais est un pastiche du début $\mathrm{du} 2 \mathrm{O}^{\mathrm{e}}$ siècle. Le volume a appartenu à plusieurs personnes qui ont tenu à le faire savoir : ex-libris imprimé de Hanns-Theo Schmitz-Otto, avec numéro 598 ; ex-libris manuscrit de H. Halling, Berlin, 1829, sur la première garde de fin. Il a aussi appartenu au baron Neufforge (cote S 245). Des notices dactylographiées concernant l'ouvrage sont collées sur les contreplats.

Le titre complet situe le propos de l'ouvrage dans l'Antiquité : Wie Pontianus der keyser zu Rom seinen sun Diocletianum den sieben weisen Meystern befilcht die sieben freien kunst zu lehren. Unnd wie der selbig hernach durch untrew seiner stieffmutter sieben mal zum galgen gefürt aber allweg durch schoene gleichnussen der Meyster vom todt erredt ein gewaltiger Keyser zu Rom ward. Lustig und nützlich wider der Weiber untrew zu lesen.

L'empereur Pontianus (qui n'apparaît pas sur les listes historiques de l'Empire romain) a un fils nommé
Dioclétien. Son épouse l'impératrice, mère de Dioclétien, vient à mourir, mais auparavant elle enjoint à son mari de faire en sorte que s'il se remarie, son fils ne soit pas soumis aux violences de sa marâtre. L'empereur confie son fils aux sept sages qui dominent alors les sept arts, afin qu'ils le forment à tous les savoirs. Puis il se remarie et la nouvelle impératrice n'a qu'une hâte : séduire le jeune Dioclétien et provoquer sa chute, voire sa mise à mort par l'empereur. Elle arrive à ses fins.

Le livre s'organise alors en courts chapitres d'argumentation : l'impératrice convainc son époux de condamner son fils, puis un des sept sages argumente pour empêcher le pire d'arriver. Et l'argumentation s'effectue à partir d'un exemple (Beispiel) et d'un symbole (Gleichnis). La somme de ces "exempla " aboutit à une espèce de recueil de fabliaux, un petit Décaméron, qui a pour sujet principal l'infidélité des femmes. Cette structure est scandée par les illustrations qui s'organisent sur le mode suivant : une dispute (aux deux sens du terme) entre l'empereur et l'impératrice, près du lit conjugal ; une scène illustrant de manière précise, et avec une légende explicite, l'exemple donné par l'impératrice ; une autre scène d'argumentation entre eux, cette fois assis sur leur trône ; le fils de l'empereur amené devant le gibet ; une scène illustrant l'exemple utilisé par le sage, ceci sept fois répété.
À la fin, le fils de l'empereur peut s'expliquer lui-même, par un exemple. La fausseté de l'impératrice et son infidélité envers son époux sont dévoilées lorsqu'une de ses dames de compagnie s'avère être un jeune homme travesti en femme. Les sept anciens sages ont pour noms Bancillas, Lentulus, Catho, Waldach, Josephus, Cleophé et Johachim.

Il s'agit du seul exemplaire de cette édition conservé en France. Peu d'exemplaires subsistent à l'étranger. Un seul est signalé pour toute l'Allemagne, à Berlin. D'autres éditions de ce livre, souvent imprimées entre 1512 et 1577, notamment à Strasbourg par Mathias Hupfuff, Cammerlander, Jacob Frölich et Christian Müller (Mylius) sont conservées dans les plus grandes bibliothèques d'Allemagne et d'Autriche. La cote de notre exemplaire est R.105.702. Le livre est visible à distance sur le site de la bibliothèque numérique de la Bayerische Staatsbibliothek.

\section{Daniel Bornemann}




\section{Soll Ditterts Det foed = ber//qäneglecionuffender fie= ben weipen meyfter.}

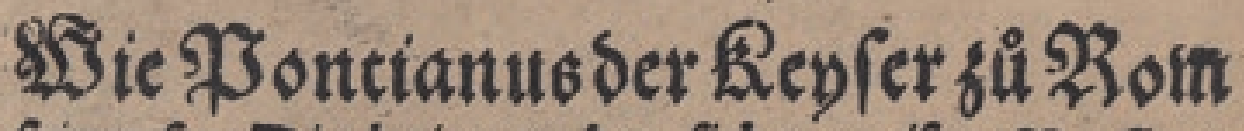
feinen fun Diocletianum den fieben weifen oDeyffetn

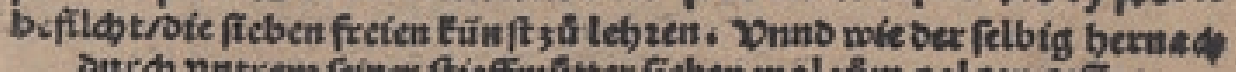
Durd) vutrew feiner ftieffintâter fieben mal ; aber allweg ourd) fojsine gleidynuffen ber hitefitex voun tooterzeot/ ein gewaltiget Beyfar stâ zRom watb. \&uftig vis nürslidh wiber ber weibet ventects silefen.

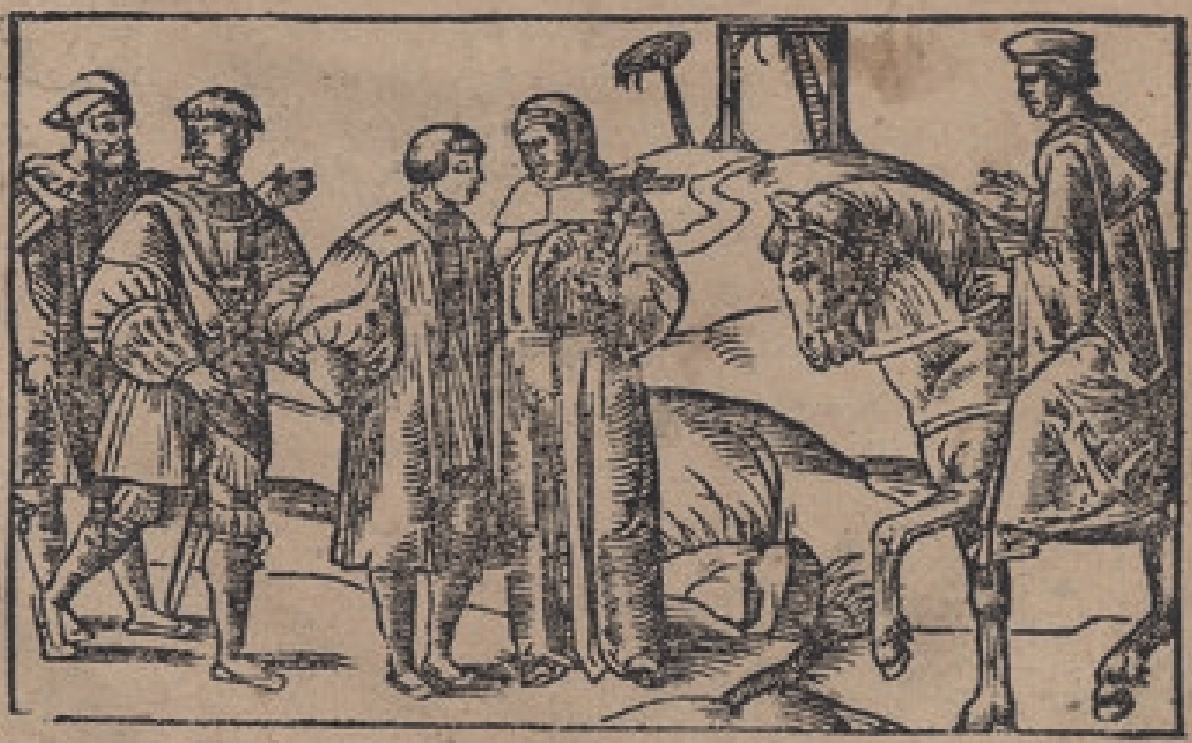

Eetrudt yí Strafburg/bey WendelXibel. Zlmo क. D. xlix. 